\title{
Hope for a cure: Attacking the inflammatory origins of cholesteatoma
}

\author{
Matthias Schürmann \\ Felix Oppel \\ Senyao Shao \\ Verena Volland-Thum \\ Christian Kaltschmidt \\ Barbara Kaltschmidt \\ Lars-Uwe Scholtz \\ Holger Sudhoff
}

\section{Video Byte}

Keywords: Cell Communication and Signaling, cholesteatoma, inflammation, TLR4, stem cells, cholesteatoma recurrence, epigenetic changes, middle ear, chronic, treatment target

Posted Date: October 16th, 2021

DOI: https://doi.org/10.21203/rs.3.rs-978688/v1

License: (1) (i) This work is licensed under a Creative Commons Attribution 4.0 International License.

Read Full License 


\section{Abstract}

Cholesteatoma is abnormal skin growth in the middle section of the ear. The resulting damage can lead to hearing loss and even facial paralysis. Unfortunately, no medical cure for cholesteatoma currently exists, and while surgical removal of excess tissue can be effective, 12 to $30 \%$ of patients show a recurrence of cholesteatoma. To understand how this abnormality forms and returns in some cases, researchers examined cholesteatoma tissue in the lab. Experiments showed that inflammatory signaling caused overactive skin cell growth. That signaling was largely mediated by the transmembrane protein TLR4, a molecule that helps orchestrate the innate immune response during infection and injury. Signs of cholesteatoma were effectively reduced by suppressing TLR4 activity with LPS-RS, a TLR4 antagonist and toxin derived from photosynthetic bacteria. By attacking the inflammatory origins of cholesteatoma, LPS-RS and other TLR4 antagonists could offer patients with cholesteatoma the hope of an effective and lasting treatment option. 